\title{
Pengaruh Metode Problem Based Learning pada Materi Redoks di Kelas X SMA Negeri 1 Wori
}

\author{
Regina Mongi ${ }^{* a}$, Meytij Rampe ${ }^{a}$, Septiany Palilingan ${ }^{a}$ \\ a Kimia, FMIPA., Universitas Negeri Manado, Minahasa, 95618, Indonesia
}

\begin{tabular}{l} 
I N F O A R T I K E L \\
\hline Diterima 05 September 2019 \\
Disetujui 27 Desember 2019 \\
\\
\hline Key word: \\
Problem Based Learning \\
Learning Outcomes \\
Redox \\
\hline Kata kunci: \\
Problem Based Learning \\
Hasil Belajar \\
Redoks \\
\hline
\end{tabular}

\begin{abstract}
A BSTRACT
The purpose of this study, to determine whether there are differences in student learning outcomes in using the Problem Based Learning method with the lecture method. During approximately 1 month different methods were applied in 2 classes, namely the Problem Based Learning class and the Lecture class with a total of 25 students each, then to see the learning outcomes a post-test was conducted. The results showed the value of $t$ arithmetic $=2.92>t$ table 2.010, so that the conclusion $\mathrm{Ha}$ is accepted and $\mathrm{HO}$ is rejected, it means there are differences in student learning outcomes using the Problem Based Learning method with those using the lecture method on redox material.
\end{abstract}

*e-mail:

reginamongi3@gmail.com

*Telp: 085340370882

\section{A BSTRAK}

Tujuan dari penelitian ini, untuk mengetahui apakah terdapat perbedaan hasil belajar siswa dalam menggunakan metode Problem Based Learning dengan metode ceramah. Selama kurang lebih 1 bulan di terapkan metode yang berbeda dalam 2 kelas yaitu kelas Problem Based Learning dan kelas Ceramah dengan jumlah siswa masing-masing 25 siswa, maka untuk melihat hasil belajar dilakukan uji post-test. Hasil penelitian menunjukkan nilai $t$ hitung $=2,92>\mathrm{t}$ tabel 2,010, sehingga kesimpulannya $\mathrm{H}_{\mathrm{a}}$ diterima dan $\mathrm{H}_{0}$ ditolak itu berarti terdapat perbedaan hasil belajar siswa yang menggunakan metode Problem Based Learning dengan yang menggunakan metode ceramah pada materi redoks.

\section{Pendahuluan}

Tantangan era globalisasi yang semakin berkembang pesat di zaman sekarang, membuat persaingan dalam menuju kesuksesan semakin ketat. Untuk itu sangat membutuhkan orang-orang yang berkompeten dan mampu bersaing dengan kualitas sumber daya yang bermut. Dalam mencapai hal tersebut sangat dibutuhkan peningkatan mutu pendidikan.

Pendidikan merupakan aspek penting dalam mencerdaskan kehidupan bangsa. Peningkatan dan perbaikan mutu pendidikan tidak dapat terlepas dari berbagai upaya [1]. Upaya-upaya yang telah dilakukan untuk meningkatkan hasil belajar siswa, masih menimbulkan masalah di hampir semua sekolah karena kurangnya peminatan siswa terhadap pelajaran-pelajaran yang lebih banyak menghitung terlebih khusus mata pelajaran kimia.Pembelajaran saat ini masih bersifat satu arah atau transfer pengetahuan dari guru ke siswa yang menitikberatkan pada penguasaan materi dan belum menuju pada aspek kecakapan hidup (life skill oriented), sehingga hasil pendidikan hanya tampak dari kemampuan siswa menghafal fakta dalam jangka pendek [2].Seorang guru haruslah lebih berinisiatif dalam menciptakan suasana pembelajaran yang nyaman sehingga siswa 
menjadi lebih tertarik untuk belajar kimia. Guru yang menjadi pemeran utama dalam proses pembelajaran harus memahami metodemetode pembelajaran yang tepat agar ketika guru memberikan pelajaran, siswa dapat memahami dan mengerti pelajaran tersebut.

Metode pembelajaran yang diduga dapat diterapkan adalah metode PBL (Problem Based Learning). Metode ini diduga mampu membantu siswa untuk lebih memahami konsep dalam memecahkan masalah melalui soal yang diberikan guru dalam materi redoks. Problem Based Learning adalah metode pembelajaran berbasis masalah yang dirancang agar siswa mendapat pengetahuan penting yang membuat mereka mahir dalam memecahkan masalah dan memiliki kecakapan dalam berpartisipasi dalam tim [3]. Dari observasi yang telah dilakukan di SMA Negeri 1 Wori, kebanyakan siswa masih menganggap mata pelajaran kimia adalah mata pelajaran yang sangat sulit dan proses belajarmengajarnya masih dinilai sangat membosankan, para guru kebanyakan masih menerapkan metode ceramah, dengan sesekali menerapkan metode demonstrasi, akan tetapi untuk metode Problem Based Learning ternyata belum pernah diterapkan di sekolah ini. Menurut data observasi yang diperoleh, hasil belajar siswa terutama pada materi redoks ternyata masih berada di bawah rata-rata nilai KKM, dan dapat dikatakan tidak lulus. KKM mata pelajaran kimia, di SMA Negeri 1 Wori yaitu 70, sedangkan rata-rata nilai siswa yang mendapat nilai 70 hanya sekitar 30\%, yang lainnya di bawah nilai KKM.

\section{Metode}

Penelitian ini dilaksanakan di SMA Negeri 1 Wori pada semester genap tahun ajaran $2018 / 2019$. Jenis penelitian yang digunakan dalam penelitian ini adalah penelitian kuantitatif dengan metode penelitian Problem Based Learning semu atau kuasi Problem Based Learning.

Tabel 1. Rancangan penelitian menggunakan Posttest Only Control Group Design berikut:

\begin{tabular}{ccc}
\hline Kelompok & Perlakuan & Posttest \\
\hline $\begin{array}{c}\text { Problem Based } \\
\text { Learning }\end{array}$ & $\mathrm{X}$ & $\mathrm{O}_{1}$ \\
\hline Ceramah & - & $\mathrm{O}_{2}$ \\
\hline
\end{tabular}

Keterangan:

$X$ : Perlakuan menggunakan metode Problem Based Learning (PBL)

- : Perlakuan menggunakan metode konvensional

$\mathrm{O}_{1}$ : Nilai posttest kelas Problem Based Learning sesudah diberi perlakuan metode pembelajaran Problem Based Learning

$\mathrm{O}_{2}$ : Nilai posttest kelas Ceramah sesudah diberi perlakuan metode pembelajaran konvensional.

\section{Hasil dan Pembahasan}

Penelitian ini dilaksanakan di SMA Negeri 1 Wori pada kelas X MIA 1 dan X MIA 2 yang dijadikan sasaran penelitian. Dengan jumlah siswa pada kelas X MIA 1 terdiri dari 25 orang, yang terdiri dari 11 orang laki-laki dan 14 orang siswa perempuan, dan pada kelas X MIA 2 juga terdiri dari 25 orang dengan jumlah siswa laki 15 orang dan jumlah siswa perempuan 10 orang. Tujuan dari penelitian ini yaitu untuk mengetahui perbedaan hasil belajar menggunakan metode pembelajaran Problem Based Learning dengan metode ceramah terhadap hasil belajar siswa pada materi redoks.

Tabel 2.Data Post-test Kelas Problem Based Learning dan Kelas Ceramah

\begin{tabular}{cccc}
\hline No & $\begin{array}{c}\text { Jenis } \\
\text { Penilaian }\end{array}$ & $\begin{array}{c}\text { Kelas } \\
\text { Problem } \\
\text { Based } \\
\text { Learning }\end{array}$ & $\begin{array}{c}\text { Kelas } \\
\text { Ceramah }\end{array}$ \\
\hline 1. & $\begin{array}{c}\text { Skor } \\
\text { Minimum }\end{array}$ & 50 & 41 \\
\hline 2. & $\begin{array}{c}\text { Skor } \\
\text { Maksimum }\end{array}$ & 91 & 83 \\
\hline 3. & Mean & 76,48 & 68,44
\end{tabular}

\section{Pengujian Instrumen Peneliian} Uji Validitas

Uji validitas soal pada penelitian ini diuji cobakan kepada 24 orang siswa kelas XI MIA 1 di SMA Negeri 1 Wori, dengan jumlah 15 bobot soal pilihan ganda, kriteria dinyatakan valid jika rhitung $>$ rtabel. 


\section{Uji Reliabilitas}

Untuk uji reliabilitas, data yang didapat yaitu $\mathrm{r}_{11}=0,773>\mathrm{r}_{\text {tabel }}=0,404$ makareliabel atau akurat data yang diukur. Maka dari itu berarti instrumen tes yang di ukur reliabel

Analisis Data

\section{Uji Normalitas}

Uji normalitas pada data yang telah di dapat, untuk kelas Problem Based Learning dan Ceramah dianalisis menggunakan Uji Liliefors. Dengan data yang telah diuji diperoleh pada perlakuan menggunakan metode Problem Based Learning, kelas Problem Based Learning Lhitung = 0,048 dan nilai Ltabel $=0,173$ pada taraf $\alpha=0,05$ dengan $n=25$. Kesimpulannya data kelas Problem Based Learning berdistribusi normal. Pada kelas Ceramah Lhitung $=0,042$ dan nilai Ltabel $=0,173$ pada taraf nyata $\alpha=0,05$ dengan $n=25$. Dengan demikian Lhitung < Ltabel maka kesimpulannya data kelas Ceramah berdistribusi normal.

\section{Uji Homogenitas}

Pada uji homegenitas mempunyai kriteria pengujian : Tolak $\mathrm{H}_{0}$ Jika Fhitung $<\mathrm{F}_{\text {tabel }}$ pada taraf nyaata $\alpha=0,05$, dengan hasil pengujian Fhitung = $1,070<F_{\text {tabel }}$ 1,96. Maka dapat disimpulkan bahwa kedua kelas adalah homogen.

Uji Hipotesis

Tabel 3. Ringkasan Uji Hipotesis

\begin{tabular}{lcc}
\hline \multicolumn{1}{c}{ Statistik } & $\begin{array}{l}\text { Kelas } \\
\text { Problem } \\
\text { Based } \\
\text { Learning }\end{array}$ & $\begin{array}{c}\text { Kelas } \\
\text { Ceramah }\end{array}$ \\
\hline $\begin{array}{l}\text { Jumlah } \\
\text { responden }\end{array}$ & 25 & 25 \\
\hline $\begin{array}{l}\text { Rata-rata } \\
\text { selisih }\end{array}$ & 76,48 & 68,44 \\
\hline $\begin{array}{l}\text { Simpangan } \\
\text { baku }\end{array}$ & 9,90 & 9,58 \\
\hline & 98,09 & 91,76 \\
\hline Varians & 2,92 & 2,92 \\
\hline $\boldsymbol{t}$ hitung & 2,010 & 2,010 \\
\hline $\boldsymbol{t}$ tabel & & \\
\hline
\end{tabular}

Dari hasil pengujian diperoleh nilai thitung $=$ 2,92 pada taraf signifikan $\alpha=0,05$ dengan derajat kebebasan $(\mathrm{dk})=48$ diperoleh $\mathrm{t}_{\text {tabel }}=$
2,010. Karena nilai thitung $>$ ttabel, maka $\mathrm{H}_{\mathrm{a}}$ diterima dan $\mathrm{H}_{\mathrm{o}}$ ditolak.

Hasil penelitian tersebut memperhatikan bahwa terdapat perbedaan hasil belajar dalam penggunaan metode Problem Based Learning pada materi redoks kelas X. Hal ini disebabkan oleh perlakuan yang diterapkan pada kedua kelas sangat berbeda, dimana pada kelas ceramah guru hanya menjelaskan dan menyampaikan materi pada siswa kemudian siswa menanggapinya dengan menjawab soal pada LKS, sedangkan pada kelas Problem based Learning, ada pembagian kelompok dan guru memberikan masalah kemudian siswa disuruh lebih berpikir kritis dan berinteraksi dengan teman sekelompok dalam memecahkan masalah yang diberikan guru, sehingga semua siswa pada kelas Problem Based Learning sangat aktif dalam proses pembelajaran dimana siswa diberikan masalah untuk dipecahkan bersama dalam kelompok. Hal ini menimbulkan perbedaan hasil belajar siswa pada kelas Problem Based Learning dan Kelas Ceramah. Sesuai dengan penelitian yang telah dilakukan dengan menggunakan metode Problem Based Learning pada materi redoks kelas $X$, metode Problem Based Learning ini mampu menciptakan interaksi antar guru dan siswa, siswa dengan siswa melalui pengelolaan yang baik pada proses pembelajaran, dengan adanya keterlaksanaan sintak pembelajaran Problem Based Learning mendorong siswa untuk meningkatkan hasil belajar, hal ini dapat dilihat dari ketercapaian siswa melalui soal post-test yang diberikan [4].

\section{Kesimpulan}

Berdasarkan hasil penelitian yang telah peneliti lakukan, maka dapat disimpulkan bahwa terdapat perbedaan hasil belajar siswa dengan menggunakan metode Problem Based Learningdengan metode ceramah pada materi reaksi reduksi-oksidasi di kelas X SMA Negeri 1 Wori.

\section{Daftar Pustaka}

1. Ratna Rosidah Tri Wasonowati.; Tri Redjeki,Sri Retno Dwi Ariani, Penerapan Model Problem Based Learning (PBL) pada Pembelajaran Hukum-Hukum Dsar Kimia Ditinjau dari aktivitas dan Hasil Belajar 
Siswa Kelas X IPA SMA Negeri 2 Surakarta Tahun Pelajaran 2013/2014.2014Pendidikan Kimia.

2. Dian Siska Rahma Fatonah, Ashadi, Haryono. "Studi Komparasi Pembelajaran Kimia Menggunakan Model Inquiry Based Learning (IBL) dan Problem Based Learning Pada materi Termokimia Kelas XI SMA N 1 Sukojjarjo Dengan Memperhatikan Kemampuan Matematik Tahun Pelajaran 2015/2016". 2016.

3. Lazulva, R. D. Penerapan Problem Based Learning konsep hidrolisis garam untuk meningkatkan hasil belajar siswa. Pendidikan kimia, 12

4. Yussi Pratiwi, Tri Redjeki, Mohammad Masykuri. Pelaksanaan Model Pembelajaran Problem Based Learning (PBL) Pada Materi Redoks Kelas X SMA Negeri 5 Surakarta Tahun Pelajaran 2013/2014. Pendidikan Kimia. 2007; 3 